\title{
Linear Chain Extension through Associative Termini
}

\author{
C. Peter Lillya,, ,la Richard J. Baker, ${ }^{\text {la }}$ Stephan Hütte, ${ }^{\text {la }}$ H. Henning Winter, ${ }^{\text {lb }}$ \\ Y.-G. Lin, ${ }^{1 \mathrm{~b}}$ Jiefeng Shi, ${ }^{1 \mathrm{c}}$ L. Charles Dickinson, ${ }^{1 \mathrm{c}}$ and James C. W. Chien ${ }^{*, 1 \mathrm{l}, \mathrm{c}}$
}

Departments of Chemistry, Chemical Engineering, and Polymer Science and Engineering, University of Massachusetts, Amherst, Massachusetts 01003

Received June 21, 1991; Revised Manuscript Received November 20, 1991

\begin{abstract}
Poly(tetramethylene oxide) (PTHF) oligomers, $\bar{M}_{\mathrm{n}}=650-2000$, have been capped with phthalate ester (2) and with phthalic half-ester (3). Properties of the latter are strongly influenced by hydrogenbonding association of carboxylic acid termini. DSC revealed new, high-temperature transitions in the carboxylterminated oligomers (3) which decreased in temperature as PTHF molecular weight increased. Esterterminated oligomers 2 have the rheological properties of simple liquids. Oligomers 3 exhibit melt viscosities and dynamic moduli which decrease sharply at the highest DSC transition temperature but nevertheless exceed those of 2 over the entire range studied. These carboxyl-terminated oligomers exhibit elasticitydominated responses to small strains with a linear viscoelastic region and good recovery to large strain amplitude oscillatory shear. All observations are consistent with formation of large crystalline aggregates of carboxyl-terminated chain ends below the high-temperature DSC transition. Solid-state ${ }^{13} \mathrm{C}-\mathrm{NMR}$ suggests the presence of phthalic half-ester end groups in both crystalline and amorphous environments.
\end{abstract}

\section{Introduction}

A material possessing good mechanical properties over its useful temperature range and having a low-viscosity melt at modestly higher temperature would offer significant processing advantages. A polymer with a temperature-dependent molecular weight-high at low temperature and low in the melt phase at higher temperaturesuggests itself. This could be a polymer with "sticky" ends which associate reversibly. Wagener ${ }^{2 \mathrm{a}}$ and Saegusa ${ }^{2 \mathrm{~b}}$ have described reversible formation of full covalent linkages. Carboxylic acid dimerization, which is rapid, is truly reversible, and has $\Delta H_{\text {assoc }}$ values of 5-10 kcal $/ \mathrm{mol}$, is strong enough to provide an ideal test case. ${ }^{3}$ Carboxyl dimer formation occurs in the crystal, liquid crystal, and liquid states. Lenz et al. ${ }^{4}$ have reported an example involving polymer liquid crystallinity which they have interpreted in terms of dimer formation by carboxylic acid chain ends.

Dissociation of hydrogen-bonded dimers by itself would cause only a gradual change of effective molecular weight and properties with temperature. Thus, we have selected crystallization as a strategy to prevent all dissociation. Test materials should have carboxylated termini capable of aggregating to form crystalline domains. Only above the melting temperature of these crystalline domains should dissociation of hydrogen-bonded dimers occur. ${ }^{4 a}$

To test this concept, we have prepared poly(tetramethylene oxide) (PTHF) oligomers having associative or nonassociative termini (Chart I). Comparative characterization of these macromolecules by DSC, solid-state ${ }^{13} \mathrm{C}-\mathrm{NMR}$, and dynamic mechanical measurements demonstrates the chain extension through associative interaction.

\section{Experimental Section}

Materials. PTHF- $650,-1000$, and -2000 were purchased from Fisher Scientific as were inorganic reagents. Organic solvents and reagents were purchased from Aldrich Chemical Co. Pyridine was refluxed over $\mathrm{CaH}_{2}$ for $24 \mathrm{~h}$ and distilled under nitrogen just prior to use. THF was refluxed with $\mathrm{Na} / \mathrm{K}$ for $72 \mathrm{~h}$ and distilled under argon just prior to use. PTHF was dried in vacuo for $24 \mathrm{~h}$ at $80^{\circ} \mathrm{C}$.

$\alpha, \omega-B i s$ ( $p$-(benzyloxycarbonyl) benzoyl) poly(tetrahydrofuran)s (2a-c). $p$-(Benzyloxycarbonyl) benzoyl chloride $(9.08 \mathrm{mmol}$ in $20 \mathrm{~mL}$ of dry THF) was added via cannula to 20 $\mathrm{mL}$ of a dry THF solution of poly(THF) $(2.46 \mathrm{~g}, 3.78 \mathrm{mmol})$
Chart I

$\mathrm{RO}\left(\mathrm{CH}_{2} \mathrm{CH}_{2} \mathrm{CH}_{2} \mathrm{CH}_{2} \mathrm{O}\right){ }_{n} \mathrm{R}$

\begin{tabular}{|c|c|c|}
\hline cmpd & $\mathrm{R}$ & $\bar{M}_{\mathrm{n}}(\mathrm{PTHF})$ \\
\hline $\begin{array}{l}1 \mathbf{a} \\
1 \mathbf{b} \\
1 \mathbf{c}\end{array}$ & $\begin{array}{l}\mathrm{H} \\
\mathrm{H} \\
\mathrm{H}\end{array}$ & $\begin{array}{r}650 \\
1000 \\
2000\end{array}$ \\
\hline $\begin{array}{l}2 \mathrm{a} \\
\mathbf{2 b} \\
\mathbf{2 c}\end{array}$ & $\begin{array}{l}\mathrm{CO}-p-\mathrm{C}_{6} \mathrm{H}_{4} \mathrm{COOCH} \mathrm{COCh}_{2} \mathrm{Ph} \\
\mathrm{CO} \cdot p \cdot \mathrm{C}_{6} \mathrm{H}_{4} \mathrm{COOCH}{ }_{2} \mathrm{Ph} \\
\mathrm{CO}-p \cdot \mathrm{C}_{6} \mathrm{H}_{4} \mathrm{COOCH}{ }_{2} \mathrm{Ph}\end{array}$ & $\begin{array}{r}650 \\
1000 \\
2000\end{array}$ \\
\hline $\begin{array}{l}3 \mathbf{a} \\
\mathbf{3 b} \\
\mathbf{3 c}\end{array}$ & $\begin{array}{l}\mathrm{CO}-p-\mathrm{C}_{6} \mathrm{H}_{4} \mathrm{COOH} \\
\mathrm{CO}-p-\mathrm{C}_{6} \mathrm{H}_{4} \mathrm{COOH} \\
\mathrm{CO}-p-\mathrm{C}_{6} \mathrm{H}_{4} \mathrm{COOH}\end{array}$ & $\begin{array}{r}650 \\
1000 \\
2000\end{array}$ \\
\hline
\end{tabular}

protected under an argon atmosphere in a Schlenk tube. Pyridine $(20 \mathrm{~mL})$ was then added, and the mixture was stirred at room temperature overnight. It was then poured into water ( 2 volumes) and shaken with ether $(3 \times 50 \mathrm{~mL})$. The combined organic layers were washed in turn with $0.1 \mathrm{~N}$ hydrochloric acid $(5 \times 50 \mathrm{~mL})$, saturated aqueous $\mathrm{NaHCO}_{3}(5 \times 50 \mathrm{~mL})$, and water $(8 \times 30 \mathrm{~mL})$ to neutrality and finally washed with saturated $\mathrm{NaCl}$ solution. The organic layer was dried with $\mathrm{K}_{2} \mathrm{CO}_{3}$ and filtered, and solvents were evaportaed under vaccum. The viscous yellow liquid was purified by flash chromatography. Flash columns were prepared with $35 \mathrm{~g}$ of silica gel $(60 \AA)$; the eluent was hexane/acetone $10 / 3$. Yellow impurities were separated after 34-36 fractions, each $15 \mathrm{~mL}$. The solvent was slowly changed to hexane/acetone $10 / 5$. Products were obtained in fractions $42-$ 52 , each $10 \mathrm{~mL}$. These fractions were combined, and the solvent was evaporated under vacuum to give $\mathbf{2} \mathbf{a}$ as a viscous, colorless liquid in $70 \%$ yield $(2.96 \mathrm{~g})$. This sample was homogeneous by TLC (silica/hexane-acetone 2:1). IR (film): $1720-1735 \mathrm{~cm}^{-1}$ (broad). ' $\mathrm{H}-\mathrm{NMR}\left(80 \mathrm{MHz}, \mathrm{CDCl}_{3}\right): \delta 1.7\left(\mathrm{t}, \beta-\mathrm{CH}_{2}\right.$ 's), $3.28(\mathrm{t}$, $\alpha-\mathrm{CH}_{2}$ 's), $4.36\left(\mathrm{t}, J=6 \mathrm{~Hz}, \mathrm{CH}_{2} \alpha\right.$ to ester), 5.39 (s, benzyl $\mathrm{CH}_{2}$ ), $7.43\left(\mathrm{~s}, \mathrm{C}_{6} \mathrm{H}_{5}\right), 8.12$ (s, phthaloyl ring $\mathrm{H}$ 's).

Polymers $2 \mathbf{b}$ and $2 c$ were prepared in an analogous fashion. The former was obtained as a colorless viscous liquid which crystallized after 10 days at $25^{\circ} \mathrm{C}$ in $73 \%$ yield. The latter was a slightly yellow viscous liquid crystallized after 4 days at $25^{\circ} \mathrm{C}$ in $78 \%$ yield.

$\alpha, \omega$-Bis(p-carboxybenzoyl)poly(tetrahydrofuran)s (3ac). Benzyl ester-terminated polymers were converted to their carboxyl-terminated analogues by hydrogenolysis. ${ }^{5}$ Polymer $2 \mathrm{a}$ $(0.95 \mathrm{~g}, 0.84 \mathrm{mmol})$ was dissolved in $10 \mathrm{~mL}$ of anhydrous methanol and $10 \mathrm{~mL}$ of dry THF. The mixture was cooled to $0^{\circ} \mathrm{C}$, and then ammonium formate $(322 \mathrm{mg})$ and a $\mathrm{Pd} / \mathrm{C}(10 \% \mathrm{Pd})$ catalyst $(322 \mathrm{mg})$ were added. The mixture was stirred $15 \mathrm{~min}$, slowly warmed to room temperature and stirred for $2 \mathrm{~h}$, filtered, and poured into $50 \mathrm{~mL}$ of water. Fifty milliliters of ether was added, 
and the mixture was shaken in turn with water $(5 \times 50 \mathrm{~mL})$, half-saturated aqueous $\mathrm{NaHCO}_{3}(2 \times 20 \mathrm{~mL}), 0.1 \mathrm{~N}$ hydrochloric acid $(2 \times 20 \mathrm{~mL})$, water to neutrality, and finally saturated $\mathrm{NaCl}$ $(2 \times 30 \mathrm{~mL})$. The organic layer was dried over $\mathrm{MgSO}_{4}$ and filtered. Then solvents were evaporated under vacuum to give $3 \mathrm{a}$ in $80 \%$ yield as a colorless oil which dried into a weak, transparent film. ${ }^{\prime} \mathrm{H}-\mathrm{NMR}\left(80 \mathrm{MHz}, \mathrm{CDCl}_{3}\right.$ ): 1.55 (t, $\beta-\mathrm{CH}_{2}$ 's), 3.35 (t, $\alpha-\mathrm{CH}_{2}$ 's), 4.32 ( $\mathrm{t}, J=6 \mathrm{~Hz}, \mathrm{CH}_{2} \alpha$ to ester end group), 8.08 (s, phthaloyl ring H's). $\bar{M}_{\mathrm{n}}$ by ${ }^{1} \mathrm{H}-\mathrm{NMR}$ integration was estimated as $710 \pm$ 40.

Polymers $3 \mathrm{~b}$ and $3 \mathrm{c}$ were prepared in an analogous fashion: 3b, weak, colorless translucent film, $80 \%$ yield, $\bar{M}_{\mathrm{n}}=1014 \pm 60$; $3 \mathrm{c}$, weak, slightly yellow translucent film, $68 \%$ yield, $\bar{M}_{\mathrm{n}}=2140$ \pm 80 .

Methods. DSC data were determined with a Du Pont 2000 thermal analyzer at a heating rate of $20^{\circ} \mathrm{C} / \mathrm{min}$ and calibrated using an In standard. After recording the first scan from -10 to $+90^{\circ} \mathrm{C}$, the specimen was cooled at a rate of ca. $20^{\circ} \mathrm{C} / \mathrm{min}$, and subsequent DSC scans were recorded until transition temperatures were reproducible.

Solid-state ${ }^{13} \mathrm{C}$-NMR spectra were obtained at $50 \mathrm{MHz}$ with an IBM 200AF spectrometer equipped with an IBM solid accessory rack and a Doty Scientific solid probe with a variabletemperature/magic-angle spinning system. The measurement conditions were as follows: $5 \mu \mathrm{s}$ for $\pi / 2$ carbon and proton pulses, spinning rate at or near $4 \mathrm{kHz}$, cross polarization by a $\pi / 2$ proton pulse followed by 2 -ms simultaneous ${ }^{13} \mathrm{C}$ and ${ }^{1} \mathrm{H}$ spin-lock, $50-\mu \mathrm{s}$ acquisition with simultaneous high-power proton decoupling, and recycle time of $3 \mathrm{~s}$. Carbon spin-lattice relaxation time $\left(T_{1}\right)$ was measured by a $\mathrm{CP}-\pi-\tau-\pi$ sequence.

${ }^{1} \mathrm{H}-\mathrm{NMR}$ spectra were recorded on an IBM NR80AF spectrometer at $80 \mathrm{MHz}$ in $\mathrm{CDCl}_{3}$ with TMS as an internal standard IR spectra were recorded on a Perkin-Elmer 1420 spectrophotometer.

\section{Results and Discussion}

Thermal Transitions. The benzyl ester-terminated oligomers resemble the PTHF oligomers from which they are derived. Both $1 \mathbf{a}$ and $1 \mathbf{b}$ are viscous liquids at room temperature. At intermediate $\bar{M}_{\mathrm{n}} \mathbf{2 \mathbf { a }}$ is a liquid while $\mathbf{2 b}$ slowly crystallized at $25^{\circ} \mathrm{C}$. The high $-\bar{M}_{\mathrm{n}}$ samples $1 \mathrm{c}$ and 2c are both soft waxy solids, $T_{\mathrm{m}} \sim 27^{\circ} \mathrm{C}$, probably due to crystallization of PTHF.

The carboxyl-terminated oligomers are all semicrystalline. Samples obtained by evaporation of diethyl ether solutions exhibited high-temperature endotherms which we associate with melting of aggregated "hard-segment" chain ends. In contrast to PTHF, $T_{\mathrm{m}}$ decreases with increasing molecular weight: 62,45 , and $36^{\circ} \mathrm{C}$ for $\mathbf{3 a}, \mathbf{3 b}$, and $3 \mathbf{c}$, respectively. Oligomer $3 \mathbf{a}$ crystallized on cooling, but second scans of $\mathbf{3 b}$ and $\mathbf{3 c}$ did not exhibit high-temperature endotherms. The observed decrease in melting temperature as hard segments are diluted by longer flexible segments is exhibited by block copolymers with microphase-separated morphology.$^{9,10}$ While these observations do not prove carboxylic acid dimerization, the strong tendency of carboxylic acids to crystallize as hydrogen-bonded dimers suggests this as a driving force for chain-end aggregation. ${ }^{11}$

Rheological Properties. Melt viscosities of the benzyl ester-terminated oligomers are very close to those of the PTHF samples from which they were derived. They exhibit frequency-independent complex viscosities above $30^{\circ} \mathrm{C}$ (Figure 1) as is typical for low molecular weight homopolymers in the low-frequency limit, indicating the absence of significant heterophase structure. At $41^{\circ} \mathrm{C}$ the corresponding carboxyl-terminated macromolecule 3a is 2.5 times more viscous than $\mathbf{2 a}$ (Figure 1).

When carboxyl-terminated macromolecules were heated above the melting temperature of the PTHF spacers $(\sim 25$ $\left.{ }^{\circ} \mathrm{C}\right)$, the samples became opalescent and exhibited un-

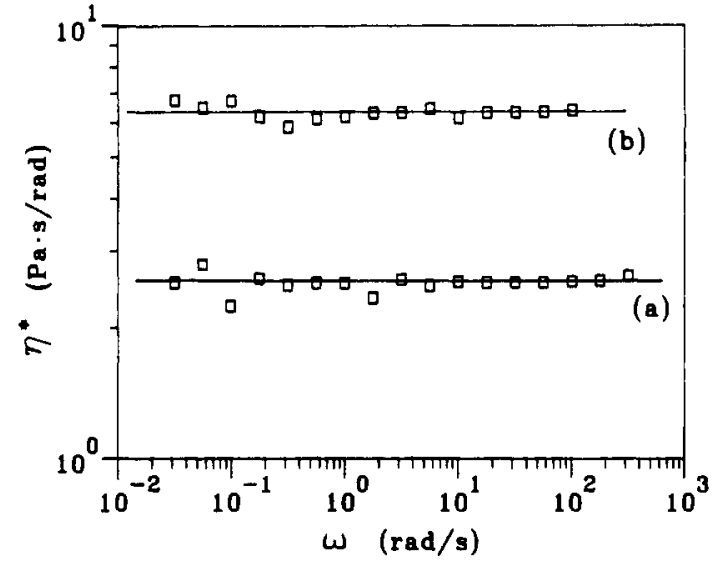

Figure 1. Variation of complex viscosity with frequency at 40 ${ }^{\circ} \mathrm{C}$ for (a) polymer $2 \mathrm{a}$ and (b) polymer $3 \mathbf{a}$.

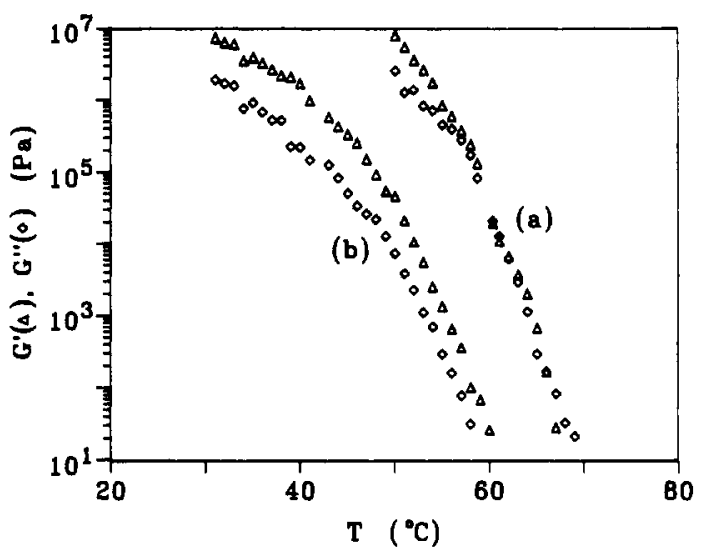

Figure 2. Variation of dynamic moduli with temperature measured at the frequency of $1 \mathrm{rad} \mathrm{s}^{-1}$ : (a) polymer 3a; (b) polymer 3b.

usually high dynamic moduli. This behavior suggests that the association of carboxyl groups is accompanied by the formation of a heterophase structure. Phase transitions were observed as a rapid decline of dynamic moduli shown in Figure 2. The midpoints of transition for polymers $\mathbf{3 a}$ and $3 \mathrm{~b}$ are about 62 and $50{ }^{\circ} \mathrm{C}$, respectively. These transition temperatures correspond closely to the hightemperature DSC transitions assigned as melting of aggregated chain termini (vide supra).

There are other differences between the heterophase state below the phase transition temperature and the simple liquid above it. The former exhibit elasticitydominant responses to very small strains in the frequency range 0.01-100 $\mathrm{rad} \mathrm{s}^{-1}$ (Figure 3). Figure 4 shows the effect of temperature and of strain on the storage modulus. In the low-strain region, the upper strain limit of the linear viscoelastic region and the value of $G^{\prime}$ decreased about 1 order of magnitude with each $5 \mathrm{~K}$ increment of temperature. This phenomenon indicates gradual dissociation of the associated termini, resulting in loss of strength in the heterophase structure and a reduction of aggregate size as the temperature increases.

Figure 5 presents an experiment in which dynamic moduli were measured first at a small strain of $0.2 \%$. When a large shear strain of $8 \%$ was applied, there was an immediate drop of moduli. Upon removal of this oscillatory shear, the dynamic moduli recovered rapidly.

Molecular Dynamics. The CP/MAS ${ }^{13} \mathrm{C}-\mathrm{NMR}$ spectra for $3 \mathrm{a}$ were obtained from -40 to $+50^{\circ} \mathrm{C}$ (Figure 6) to investigate the molecular dynamics. Peak assignments are listed in Table I. The small peak adjacent to and on 


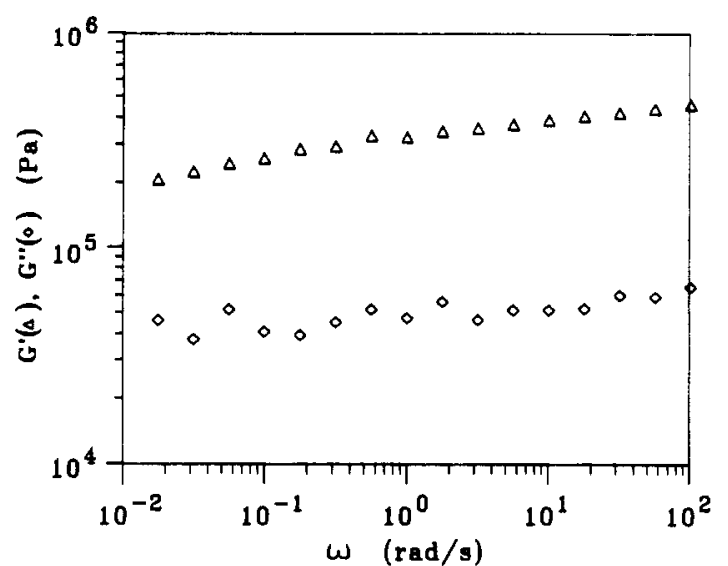

Figure 3. Variation of $G^{\prime}(\Delta)$ and $G^{\prime \prime}(\diamond)$ with frequency for polymer $3 \mathrm{~b}$ at $45^{\circ} \mathrm{C}$.

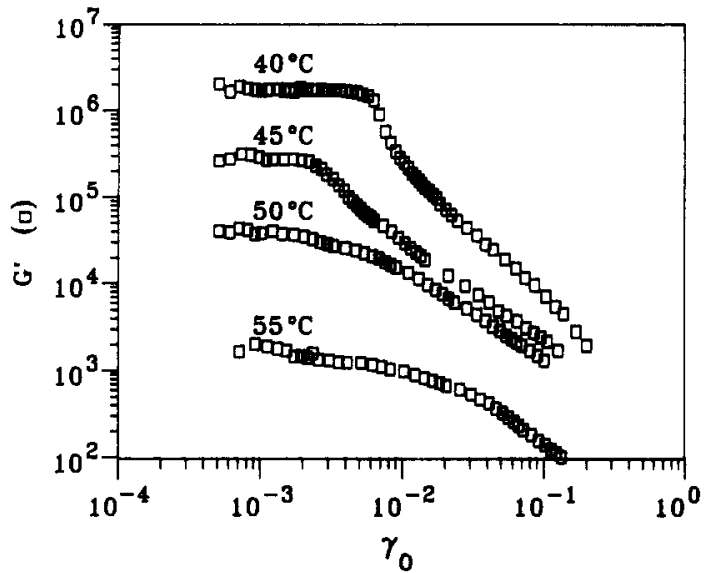

Figure 4. Variation of $G^{\prime}$ with strain for polymer $\mathbf{3 b}$ at various temperatures measured at $1 \mathrm{rad} \mathrm{s}^{-1}$.

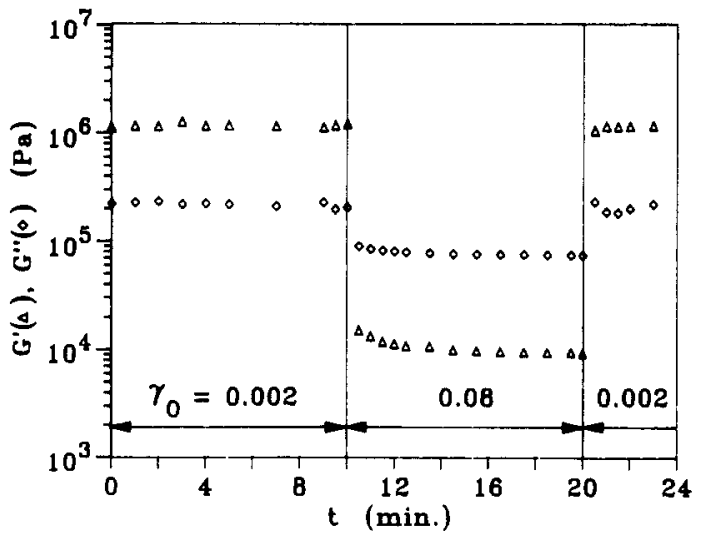

Figure 5. Recovery of dynamic moduli after large strain amplitude oscillatory shear for polymer $3 \mathrm{~b}$ at $41^{\circ} \mathrm{C}$ and $1 \mathrm{rad}$ $\mathbf{s}^{-1}$

the upfield side of the $\mathrm{OCH}_{2}$ resonance is the terminal $\mathrm{OCH}_{2} \alpha$ to the ester carbonyl. The ${ }^{13} \mathrm{C}$ spin-lattice relaxation times are given in Table II.

The $\mathrm{CH}_{2}$ resonances contain both a crystalline component at $27.0 \mathrm{ppm}$ and a noncrystalline component at $26.4 \mathrm{ppm}$. The same is true for the $\mathrm{OCH}_{2}$ carbons with resonances at 72.0 and $70.4 \mathrm{ppm}$ for the crystalline and amorphous components, respectively. They shift downfield with decreasing temperature. These asymmetric peaks were analyzed in terms of two Lorentzian functions as shown in Figure 7. Peak positions, line widths, and heights were varied to fit the observed spectrum. The variations of line width with temperature are shown in
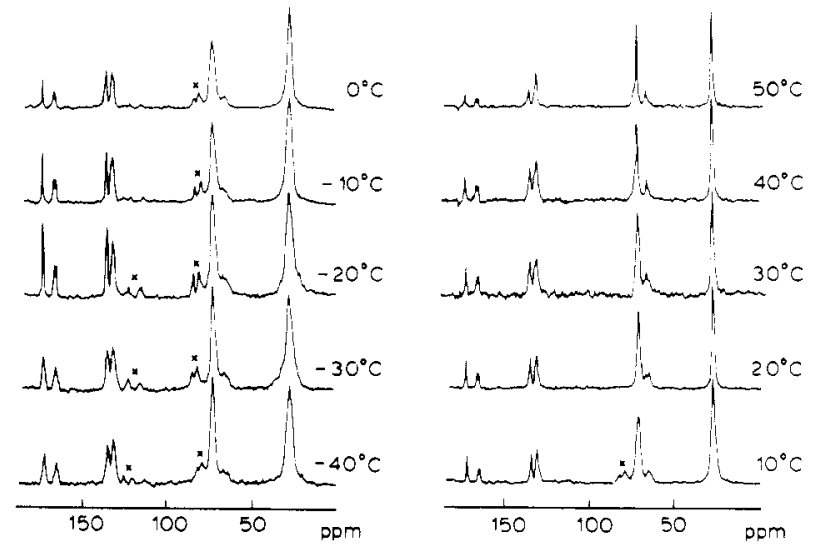

Figure 6. CP/MAS ${ }^{13} \mathrm{C}-\mathrm{NMR}$ of polymer $3 \mathrm{a}$ from -40 to +50 ${ }^{\circ} \mathrm{C}$.

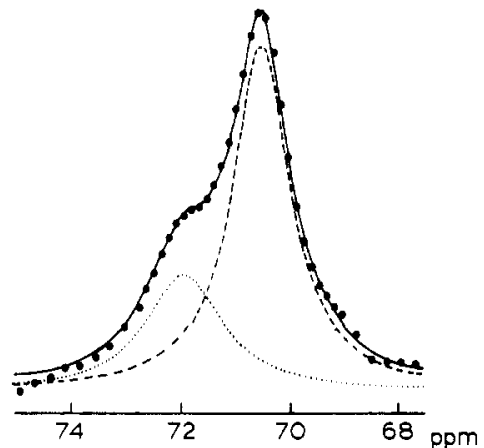

Figure 7. Line-shape analysis of the $\mathrm{OCH}_{2}$ resonance.

Table I

${ }^{13} \mathrm{C}$ Chemical Shifts (ppm) for $3 \mathrm{a}$ at Various Temperatures

\begin{tabular}{ccccccc}
\hline temp, ${ }^{\circ} \mathrm{C}$ & $\mathrm{CH}_{2}$ & $\mathrm{OCH}_{2}$ & $\mathrm{C}_{\text {ar1 }}{ }^{a}$ & $\mathrm{C}_{\text {ar2 }}{ }^{b}$ & COOR & $\mathrm{COOH}$ \\
\hline 50 & 26.4 & 70.4 & 129.7 & 133.7 & $164.0 / 164.8$ & 171.4 \\
40 & 26.6 & 70.4 & 129.9 & 133.9 & $164.0 / 165.0$ & 171.5 \\
30 & 26.4 & 70.4 & 130.0 & 133.9 & $164.1 / 164.9$ & 171.3 \\
20 & 26.6 & 70.5 & 130.3 & 133.9 & $164.0 / 164.9$ & 171.3 \\
10 & 26.6 & 70.7 & 130.3 & 133.7 & $163.7 / 164.7$ & 171.3 \\
0 & 26.6 & 72.0 & 130.6 & 133.7 & $163.7 / 164.8$ & 171.4 \\
-10 & 26.9 & 72.0 & 130.5 & 133.7 & $163.7 / 184.7$ & 171.4 \\
-20 & 27.0 & 72.0 & 130.5 & 133.7 & $163.7 / 164.7$ & 171.4 \\
-30 & 27.4 & 72.0 & 130.5 & 133.7 & 164.3 & 171.2 \\
-40 & 27.6 & 72.1 & 130.5 & 133.7 & 164.2 & 171.2
\end{tabular}

${ }^{a}$ Protonated aromatic carbons. ${ }^{b}$ Unprotonated aromatic carbons.

Table II

${ }^{13} \mathrm{C}$ Spin-Lattice Relaxations for $3 \mathrm{a}$ at Room Temperature

\begin{tabular}{ccl}
\hline carbon type & chem shift, ppm & $T_{1},{ }^{\mathrm{c}} \mathrm{s}$ \\
\hline $\mathrm{C} * \mathrm{H}_{2}$ & 26.4 & 0.1 \\
& 27.0 & 27 \\
$\mathrm{OC} * \mathrm{H}_{2}$ & 70.4 & 0.1 \\
& 72.0 & 55 \\
$\mathrm{C}^{*}{ }_{\text {ar1 }}$ & 130.3 & 4,76 \\
$\mathrm{C}_{\text {ar2 }}$ & 133.9 & 10,104 \\
$\mathrm{C}{ }^{*} \mathrm{OOR}$ & $164.0 / 164.9$ & 7,75 \\
$\mathrm{C} * \mathrm{OOH}$ & 171.3 & 90
\end{tabular}

Figure 8. The decrease of line width with increasing temperature suggests two transitions, one at ca. $-40^{\circ} \mathrm{C}$ and the other at $+20^{\circ} \mathrm{C}$. However, variation for the $\mathrm{OCH}_{2}$ line width at $70.4 \mathrm{ppm}$ is monotonic.

The $\mathrm{OCH}_{2}$ and $\mathrm{CH}_{2}$ carbons exhibit two $T_{1}$ values at different chemical shift positions. The upfield line with the shorter $T_{1}$ and the downfield line with the longer $T_{1}$ are assigned to the noncrystalline (a) and crystalline (c) components, respectively. The total ${ }^{13} \mathrm{C}$ magnetization 

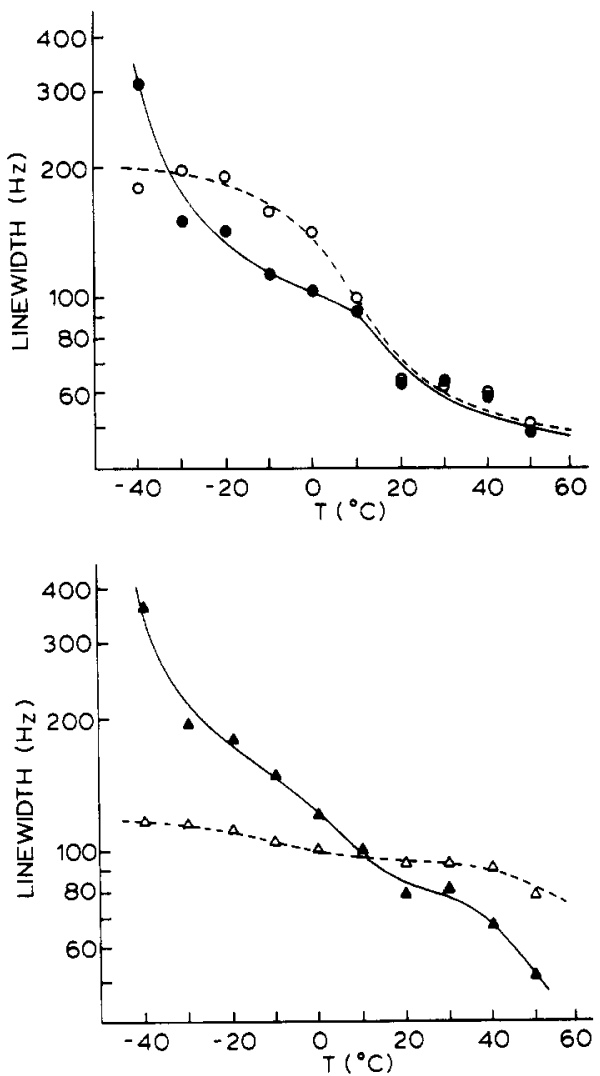

Figure 8. Variation of line widths with temperature: (a, top) the $\mathrm{CH}_{2}$ resonance [(O) $27.0 \mathrm{ppm} ;(\bullet) 26.4 \mathrm{ppm}$ ]; (b, bottom) the $\mathrm{OCH}_{2}$ resonance $[(\Delta) 72.0 \mathrm{ppm} ;(\Delta) 70.4 \mathrm{ppm}]$.

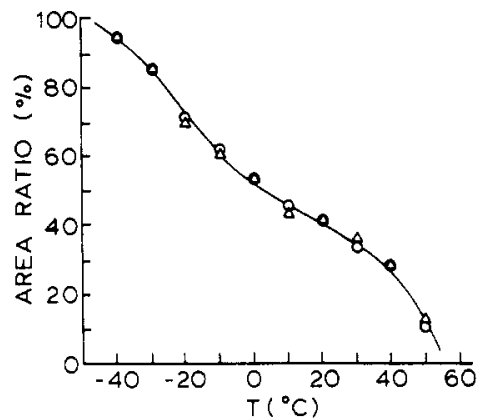

Figure 9. Variation of mass fraction of $\mathrm{OCH}_{2}$ and $\mathrm{CH}_{2}$ carbons; symbols as in Figure 8.

$M(t)$ is given by the equation

$$
\begin{aligned}
& M(t)=M_{0, \mathrm{a}} \exp \left[1-2 \exp \left(-t / T_{1, \mathrm{a}}\right)\right]+ \\
& M_{0, \mathrm{c}} \exp \left[1-2 \exp \left(-t / T_{1, \mathrm{c}}\right)\right]
\end{aligned}
$$

The integrated mass fractions of the $\mathrm{CH}_{2}$ and $\mathrm{OCH}_{2}$ peaks from line-shape analysis are shown as a function of temperature in Figure 9. The crystalline phases of these carbons gradually change to noncrystalline phases with increasing temperature. There are appreciably sharper changes at ca. -30 and $+50^{\circ} \mathrm{C}$. Of course, the integrated mass fraction is not a quantitative measure because of possible differences in the cross polarization for various carbon types in the crystalline and amorphous domains and as functions of temperature.

The ester carbonyl peak resolves into two components; their line widths both decrease significantly at $-30{ }^{\circ} \mathrm{C}$ (Figure 10) and have two $T_{1}$ values. The aromatic carbons also exhibit two different $T_{1}$ 's. The shorter $T_{1}$ lies between 4 and $10 \mathrm{~s}$; the longer $T_{1}$ 's have values of 75-104 s. The two distinct lines for the ester carbonyl carbons suggest

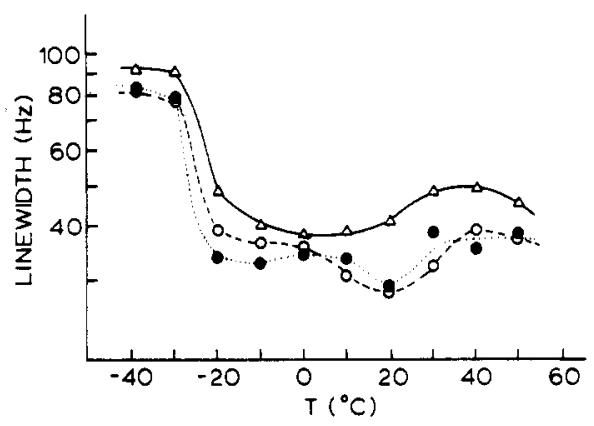

Figure 10. Variation of line width with temperature: ester car-

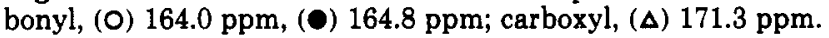
that two ester conformations may exist. Similar conformations were observed by ${ }^{13} \mathrm{C}-\mathrm{NMR}$ for the ester group coupling the mesogenic terminal groups to the spacer in the twin liquid crystalline macromolecules. ${ }^{12}$

The doublet of the carbonyl carbon coalesces at $-30^{\circ} \mathrm{C}$. The noncrystalline component of the $\mathrm{OCH}_{2}$ at $70.4 \mathrm{ppm}$ disappears at $-40^{\circ} \mathrm{C}$. These changes are due to motion effects and may correspond to a glass transition. There is a secondary relaxation transition at room temperature.

The carboxyl carbon resonance was a singlet, and its chemical shift was temperature independent. Its linewidth change with temperature parallels that at the ester carbonyl. These observations are consistent with complete carboxylic acid dimerization over the temperature range -40 to $+50^{\circ} \mathrm{C}$.

Conclusion. Carboxylic acid-terminated PTHF oligomers exhibit properties markedly different from those of their benzyl ester-terminated analogues. They exhibit "high-temperature" DSC endotherms, whereas benzyl ester-terminated PTHF samples do not. Rheological measurements reveal unusually high complex moduli for the carboxy-terminated oligomers and document their dramatic decrease as the temperature range of the hightemperature DSC transition is traversed. Below this transition, they behave as elasticity-dominated heterophases. In contrast, PTHF and benzyl-terminated PTHF behave as simple viscous liquids at all temperatures above ambient. These observations lead to the conclusion that, driven by carboxylic acid dimerization, carboxylated chain ends aggregate to form crystalline domains which function as physical cross-links. Solidstate ${ }^{13} \mathrm{C}-\mathrm{NMR}$ spectroscopy reveals two signals with strikingly different relaxation times for several end groups and PTHF carbons. These have been interpreted in terms of crystalline and amorphous regions. The $\mathrm{COOH}$ signal is temperature-independent, indicating nearly complete $\mathrm{H}$-bonded dimer formation in the temperature range -40 to $+50^{\circ} \mathrm{C}$.

\section{References and Notes}

(1) (a) Department of Chemistry. (b) Department of Chemical Engineering. (c) Department of Polymer Science and Engineering.

(2) (a) Wagener, K. B.; Engle, L. P.; Woodward, M. H. Macromolecules 1991, 24, 1225. (b) Chujo, Y.; Sada, K.; Saegusa, T. Macromolecules 1990, 24, 2636.

(3) While hydrogen bond polymer-polymer interactions in biomacromolecules are well documented, e.g., in DNA, collagen, and enzymes, these involve primarily "side-to-side" interactions. Our work is directed toward "end-to-end" interactions.

(4) Hoshino, H. Jin, J.I. Lenz, R. W. J. Appl. Polym. Sci. 1984, 29,547 . (a) Note added in proof: For a realization of a similar concept in statistically substituted polybutadienes, see: Hilger, C.; Stadler, R. Polymer 1991, 32, 3244

(5) Kelly, R. C.; Gebhard, I.; Wienienski, N. J. Org. Chem. 1986. $51,4590$.

(6) Zahr, H.; Seidel, B. Makromol. Chem. 1959, 29, 70.

(7) Hässlin, H. W.; Dröscher, M.; Wegner, G. Markomol. Chem. $1980,181,301$. 
(8) After the method of: Ober, C.; Lenz, R. W.; Galli, G.; Chiellini, E. Macromolecules 1983, 16, 1034 .

(9) Legge, N.-R.; Holder, G.; Schroder, H. E., Eds. Thermoplastic Elastomers: A Comprehensive Review; Hanser Publishers: Munich, 1981.

(10) (a) Limura, K.; Koide, N.;Ohta, R.; Takeda, M. Makromol. Chem. 1981, 182, 2563. (b) Jin, J. I.; Antoun, S.; Ober, C.; Lenz, R. W. Br. Polym.J. 1980, 12, 132. Lenz, R. W. J. Polym. Sci., Polym. Symp. 1985, 72, 1. (c) Gedhiski, Z.; Franck, J.; Kuziw, P. Makromol. Chem. 1986, 187, 2317.
(11) (a) Cf.: Desiraju, G.-R. Crystal Engineering, The Design of Organic Solid; Elsevier: Amsterdam, 1989. (b) Leisaowitz, L. Acta Crystallogr. 1987, B32, 775 .

(12) Chu, C. W.; Dickinson, L. C.; Chien, J. C. W. Macromolecules $1992,25,201$.

Registry No. la (copolymer), 24979-97-3; la (SRU), 25190 06-1; 2a, 139408-82-5. 